\title{
Progress made in maternal and child health, but challenges remain
}

Published at www.cmaj.ca on Oct. 28

$\mathrm{H}$ ow can you tell if a country's health care system is functioning well? Is life expectancy the key indicator, or wait times? Maybe it's a matter of dollars spent on health care or efficiencies achieved in hospitals? Or maybe the answer can be found in maternity wards and pediatric departments, suggests Bridget Lynch, a board member of the Partnership for Maternal, Newborn and Child Health.

"If maternal health and child health are good, it is de facto a good health care system," Lynch told delegates to an Oct. 27 session on the role of government in global health diplomacy at the 16th Canadian Conference on International Health in Ottawa, Ontario.

A society has little chance to thrive if it fails to keep its mothers healthy and its babies alive, suggested Lynch. But young children in developing nations continue to suffer preventable deaths in alarming numbers. Nine million children under age five die annually $-40 \%$ in the first weeks of their lives. The mothers of these children often don't fare much better. More than 500000 women around the world die of pregnancy-related causes each year. This problem, though of immense scale, has historically attracted little attention from policy makers or the public.

"Women have been so invisible for so long," said Lynch.

There has, however, been some progress since 2005, when the Partnership for Maternal, Newborn and Child Health - a coalition of about 300 organizations working under a World Health Organization umbrella - was established. Some countries have seen sharp declines in infant mortality. More children around the world are receiving vaccines and vitamin A supplements.

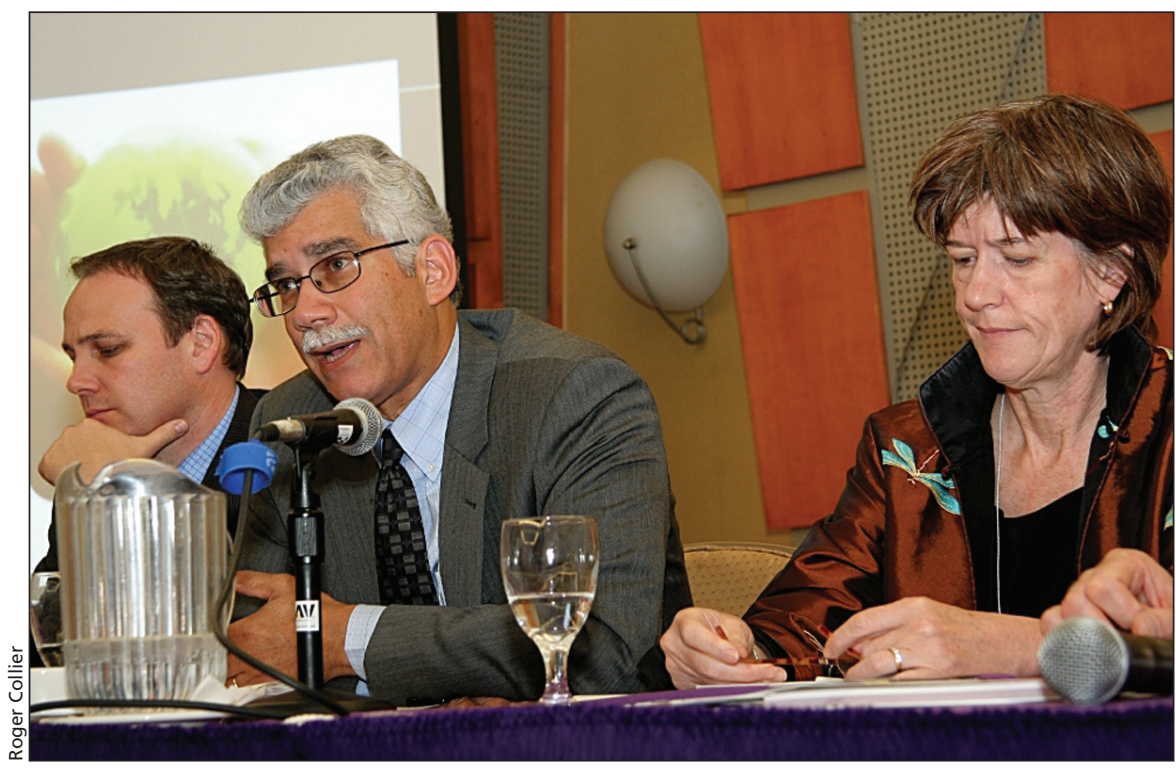

Christopher MacLennan (left), Alex Palacios (centre) and Bridget Lynch (right) discuss the role of government in addressing global health issues such as maternal and child health.

Several high-profile people have chosen to champion maternal mortality reduction, including United Nations Secretary-General Ban Ki-Moon and Sarah Brown, wife of British Prime Minister Gordon Brown.

The most significant change, perhaps, is that political leaders have in recent years recognized the importance of improving maternal and infant health. In 2008, for the first time, leaders of the G8 nations committed to address these issues as part of a comprehensive approach to delivering basic health care. Reducing infant mortality and improving maternal health are also two of the eight Millennium Development Goals (MDGs) that 192 United Nations member states have agreed to achieve by 2015 .

"To get maternal health into the MDGs was an enormous challenge," said Lynch.

Other challenges remain.

These include a lack of consensus on a core package of interventions for mothers and children at risk, insufficient coordination of the purchasing and delivery of commodities for maternal and child health, and the dearth of health workers dedicated to making universal coverage of reproductive, maternal, newborn and child health services a reality. Another major problem is that it takes a very long time to get new vaccines and immunizations for children into developing nations.

"When a new vaccine is developed, it can take 15 years before it reaches people in poor countries. In the meantime, kids die," said Alex Palacios, a special representative of the executive office of the Global Alliance for Vaccines and Immunizations, who was on the panel with Lynch.

The need for increased funding to address maternal and child health issues is also a major challenge. And in a world rife with problems in many areas outside of health, getting governments to commit more money to specific health issues will remain a challenge, 
suggested Christopher MacLennan, director general of the Canadian International Development Agency and the third member of the panel.

Donor states, such as Canada, must choose between many competing priorities when giving money to developing nations. And sometimes these nations don't have health matters — as important as they may be - at the top of their lists. Even if health is a priority, there are still many different problems — from HIV/AIDS to malaria to malnutrition that need to be addressed.

"Not only does global health have to compete with other priorities, such as trade and agriculture, it has to compete with itself," said MacLennan. "The most fundamental way to get additional funding is to show that the money currently being spent is having an impact." — Roger Collier, CMAJ

DOI:10.1503/cmaj.109-3091 